\title{
LAZER E EDUCAÇÃO EM PARQUES URBANOS: A COMUNICAÇÃO VISUAL NO PARQUE IBIRAPUERA
}

\author{
LEISURE AND EDUCATION IN URBAN PARKS: THE VISUAL \\ COMMUNICATION IN IBIRAPUERA PARK
}

\section{LAZER Y EDUCACIÓN EN PARQUES URBANOS: LA COMUNICA- CIÓN VISUAL EN EL PARQUE IBIRAPUERA}

\author{
Karine Regina FACINI ${ }^{1}$ \\ DANILO DOS SANTOS LOPES ${ }^{1}$ \\ RICARDO RICCI UVINHA ${ }^{1}$ \\ Universidade de São Paulo (USP), São Paulo/SP - Brasil ${ }^{1}$
}

Resumo O presente trabalho se insere no eixo temático Lazer, Tecnologias de Informação e Comunicação e se relaciona ao usufruto do turismo em parques urbanos, analisando a comunicação visual no Parque Ibirapuera como um dos elementos essenciais da hospitalidade. O procedimento metodológico adotado foi o qualitativo, combinando observação participante e aplicação de questionário semiestruturado. A observação participante permitiu verificar a carência de sinalização em geral, tanto nos portões que dão acesso ao parque, como no interior do mesmo. A partir da coleta de dados, foi possível compreender que a maior parte dos entrevistados aponta a comunicação visual do mesmo com o conceito regular, ressaltando que a sinalização é insuficiente para direcionar um público em tal parque, em especial nos finais de semana. Sendo assim, conclui-se que a comunicação visual é um elemento importante para a educação no lazer, tornando o ambiente mais hospitaleiro e que, nesse sentido, o Parque Ibirapuera não parece um ambiente tão acolhedor quanto poderia. Propõem-se, como possíveis soluções: a inserção de sinalização em locais estratégicos do parque, a promoção do aplicativo de celular desenvolvido pelo próprio parque e sua disponibilização em mais dois idiomas (inglês e espanhol), bem como a contratação de guias de turismo e animadores socioculturais para atender e orientar os visitantes.

Palavras-chave: Lazer; Turismo; Hospitalidade; Comunicação Visual; Parque Ibirapuera. 
Abstract This present research is part of the thematic axis Leisure, Information and Communication Technologies and is related to tourism usufruct in urban parks, analyzing the visual communication in Ibirapuera Park as one of the essential elements of hospitality. The methodological procedure adopted was qualitative, combining participant observation and semi-structured questionnaire application. The participant observation made it possible to verify the lack of signs in general at the gates that give access to the park and inside the park. From the data collection, it was possible to understand that most of the interviewees indicated the visual communication of the park with the regular concept, emphasizing that the signaling is insufficient to direct a public in such park especially on weekends. Therefore, it is concluded that visual communication is an important element for leisure education, making the environment more hospitable and in this sense, the Ibirapuera Park does not seem to be as welcoming an environment as it could be. Possible solutions are: the signage insertion in park strategic locations, the mobile application promotion developed by the park itself and its availability in two more languages (English and Spanish), as well as the contracting of tourist guides and socio-cultural animators to meet and guide visitors. Keywords: Leisure; Tourism; Hospitality; Visual Communication; Ibirapuera Park.

Resumen El presente trabajo se inserta en el eje temático Ocio, Tecnologías de Información y Comunicación y se relaciona con el disfrute del turismo en parques urbanos, analizando la comunicación visual en el Parque Ibirapuera como uno de los elementos de la hospitalidad. El procedimiento metodológico adoptado fue el cualitativo, combinando observación participante y aplicación de cuestionario semiestructurado. La observación participante permitió verificar la carencia de señalización en general en las puertas que dan acceso al parque y en su interior. A partir de la recolección de datos fue posible comprender que la mayor parte de los entrevistados apunta la comunicación visual del parque con el concepto regular, resaltando que la señalización es insuficiente para dirigir a un público especialmente los fines de semana. Se concluye que la comunicación visual es un elemento importante para la educación en el ocio, haciendo el ambiente más hospitalario y que en ese sentido, el Parque Ibirapuera no parece ser un ambiente tan acogedor como podría. Se proponen como posibles soluciones: la inserción de señalización en lugares estratégicos del parque, la promoción de la aplicación de celular desarrollado por el propio parque y su disponibilidad en dos idiomas (inglés y español), así como la contratación de guías de turismo y animadores socioculturales para atender y orientar a los visitantes.

Palabras clave: Ocio; Turismo; Hospitalidad; Comunicación Visual; Parque Ibirapuera.

\section{INTRODUÇÃo}

Desde os primórdios da humanidade, os indivíduos se deslocam em direção a outros lugares com motivações e objetivos distintos. O que, anteriormente, guiava esses viajantes era a busca por condições que garantissem sua sobrevivência. Com o passar do tempo, o deslocamento adquiriu novas formas e interpretações, tornando-se o que se entende hoje por 
turismo: "[...] pessoas viajando e permanecendo em lugares fora de seu ambiente habitual por não mais do que um ano consecutivo para lazer, negócios e outros fins" (OMT, 1995).

Quando o assunto é turismo, há diferentes elementos a serem considerados. Beni $(1998)$ destaca em sua obra que, quando o turista ou visitante deseja ir a determinado destino, alguns "fatores psicológicos" influenciam sua tomada de decisão, como: a percepção, o aprendizado, a personalidade, a motivação e as atitudes. Em outras palavras, o autor implica que, para ir a um local novo ou mesmo para retornar a um local conhecido é necessária uma boa percepção do mesmo, encontrando oportunidades de aprendizado que, de algum modo, relacione a experiência com sua própria personalidade; sentir-se motivado com atitudes que transformem o visitante de alguma maneira.

Todos os fatores psicológicos são relevantes em maior ou menor grau, porém destacam-se dois em especial: percepção e motivação. Tomando como exemplo a situação pela qual passa a cidade do Rio de Janeiro atualmente, com uma crise inequívoca de segurança, haveria motivação para visitá-la ainda que seja um dos destinos turísticos mais procurados tanto por brasileiros quanto por estrangeiros? Se a resposta for positiva, implica-se uma boa percepção do destino mesmo diante do cenário adverso atual. Se a resposta for negativa, pode-se cogitar que a decisão foi pautada pela percepção de que a cidade não é um bom local para ser visitado no momento. ${ }^{1}$

Nesse sentido, essa percepção ou o que o autor Urry (1996) intitula como "olhar do turista" são construídos histórica e socialmente, sofrendo alterações de acordo com o contexto social em que esse turista encontra-se inserido. Logo, não existe apenas um olhar, mas diferentes olhares sobre um mesmo destino turístico, podendo ser positivos ou negativos.

Assim, quando determinado destino turístico é visto por meio de uma perspectiva negativa, o turista não se sente motivado a deslocar-se até esse local. Esse sentimento (negativo) provocado pela percepção é exatamente o oposto do que se espera de um turista, o qual deveria sentir o desejo de visitar um local, de permanecer nele e de saber mais, pois o mesmo causa uma sensação de bem-estar e o faz sentir-se bem só de imaginar-se lá.

De fato, tais olhares e estímulos construídos previamente às viagens são fatores importantes e determinantes, em alguns casos, para o deslocamento dos turistas, porém não são os únicos influenciadores. Afinal, muitos turistas viajam especialmente porque construíram um bom olhar prévio e criaram inúmeras expectativas positivas sobre determinado destino turístico. Sendo assim, outro fator relevante a ser destacado é a hospitalidade, que pode (ou não) acontecer entre moradores locais (anfitriões) e turistas (hóspedes).

Sabe-se que a hospitalidade está comumente associada a hotéis, visto que há, nesses ambientes, um anfitrião, um hóspede e até uma regra de conduta claramente definida. Do mesmo modo, pode-se entender a hospitalidade em um aniversário de família (organizado pelo aniversariante e, não raro, desfrutado principalmente pelos visitantes). Logo, a hospitalidade é muito mais abrangente; ela pode ocorrer em diversos locais e espaços inusitados,

Notícia informa que "Rio perdeu R $\$ 657$ milhões em turismo por causa da violência": $<$ http://agenciabrasil.ebc.com.br/economia/noticia/2017-10/rio-perdeu-r-657-milhoes-em-turismo-por-causa-da-violencia -diz-cnc>. 
por assim dizer. Conforme demonstrado aqui, uma cidade - um conglomerado de pessoas e espaços - pode ser considerada hostil ou hospitaleira, não apenas pela violência na mesma, mas por um conjunto de fatores que afetam a percepção do visitante.

Visto que a hospitalidade implica o ato de receber e ser recebido - não necessariamente se restringindo aos hotéis -, nesse sentido, ela também pode ser observada em parques públicos de uma cidade. Tomando como exemplo o Parque Ibirapuera, localizado na cidade de São Paulo, a hospitalidade pode ser analisada a partir da comunicação visual ou pela sinalização disponibilizada no parque. Dessa forma, entende-se que o parque assume a posição de anfitrião, assim como os visitantes se tornam hóspedes dele.

Isso posto, este artigo objetiva analisar a comunicação visual do Parque Ibirapuera, considerando-a como um elemento importante da hospitalidade. Para tanto, utiliza-se como referencial teórico os conceitos de hospitalidade e de comunicação visual, com o intuito de entender, não somente o que significam isoladamente, mas também a relação entre ambas. E, por fim, tal análise conta com a observação participante dos pesquisadores e com a aplicação de um questionário semiestruturado aos visitantes do parque a fim de captar a percepção dos mesmos com respeito à sinalização do local.

\section{HoSPITALIDAde E COMUNICAÇÃo: RELACIONANDO CONCEITOS}

A palavra hospitalidade possivelmente surgiu na Europa em meados do século XIII. Com origem no latim hospitalis, o termo faz referência às antigas hospedagens que recebiam não somente viajantes, mas também enfermos e doentes mentais (GRINOVER, 2002). É cabível observar que a palavra hospitalidade já esteve relacionada a espaços muito específicos, como hospitais, hospícios e, mais contemporaneamente, a hotéis - fato que nos remete à ideia de recebimento e cuidado para com quem assume a posição de um hóspede.

Embora, recentemente, esteja quase sempre associada à hotelaria, a hospitalidade não se restringe a esse, nem a qualquer ambiente, pois independe do espaço social. Conforme salienta o autor Camargo (2004; 2015), a hospitalidade pode ocorrer em diferentes espaços, como domésticos, públicos, comerciais e virtuais (lares, parques públicos, hotéis, internet). Afinal, o que realmente define a hospitalidade, não é o local, mas sim a troca que acontece entre dois (ou mais) agentes; a relação humana, interpessoal, entre o anfitrião e o hóspede - receber e ser recebido.

Em outras palavras, a hospitalidade é uma dádiva que se dá num processo de dar, receber e retribuir, onde um oferece algo ao outro e, este que o recebe, retribui tal dádiva. Inclusive, tal processo é encarado como uma obrigação, levando a um ciclo sem fim, ou seja, a um novo dar, receber e retribuir (CAMARGO, 2004; MAUSS; LÉVI-STRAUSS; MARQUES, 2008).

Porém, esse ciclo da dádiva (dar, receber e retribuir) só continuará existindo se o hóspede se sentir motivado a retribuir a hospitalidade com a qual fora recebido; ou seja, se for bem recebido e tratado pelo seu anfitrião. Para tanto, o anfitrião deve possuir algumas das qualidades do ser hospitaleiro, zelando pelo cuidado e bem-estar do outro (GUIMARÃES; CAMARGO, 2017). 
Visto que a hospitalidade diz respeito às relações humanas, mais precisamente, às relações interpessoais entre anfitrião e hóspede, pode-se entender que é impossível que ela se concretize sem a comunicação (independente de sua forma) entre tais agentes, pois conforme constata-se, a hospitalidade "[...] se dá no momento do encontro e por meio da comunicação" (DENCKER, 2007, p. 97).

O autor Trigo (1993, p. 25) analisou as tendências contemporâneas para a qualidade do turismo e, no momento em que discutiu as formações sociais pós-industriais, fez uma reflexão bem interessante: "a informação bem administrada é mercadoria muito valiosa. Ela garante riqueza, poder e legitimidade ao seu proprietário". Isso corrobora com o dito popular de que "conhecimento é poder", porém essa informação só é valiosa se bem administrada. Desse modo, de nada adianta viver na era da tecnologia da informação e ter a melhor informação, se não souber o que fazer com ela.

Informação por si só não tem valor; ela passa a ter valor quando é compartilhada; quando é comunicada. Daí a importância da comunicação para as relações sociais, seja no mundo contemporâneo e tecnológico em que vivemos, seja numa sociedade mais primitiva.

De acordo com alguns dicionários, a palavra comunicação significa o ato de transmitir ou compartilhar mensagens e, portanto, pode ser entendida como a troca de informações entre agentes. Visto que está relacionada, principalmente, às relações humanas, a comunicação não se resume a uma forma específica, mas principalmente à transmissão de ideias, princípios, dados, figuras etc. (PENTEADO, 1980).

Nesse sentido, há diferentes tipos de comunicação, como a verbal, a não verbal, a visual, entre outras. Diferente da comunicação verbal e não-verbal que dizem respeito à linguagem falada e corporal dos seres humanos, a comunicação visual é representada por símbolos (figuras), os quais podem ser visualizados em placas informativas em geral, outdoors, letreiros etc., espalhados ao redor da cidade (SILVA et al., 2000; JÜNGE, 2011).

Com base nisso, conclui-se que a comunicação pode transcender as relações sociais, pois vai muito além do encontro e do diálogo entre dois ou mais indivíduos, representados por seres humanos, respectivamente entre anfitrião e hóspede, pois também faz referência à imagens e símbolos. No caso da comunicação visual - que é analisada neste artigo -, ela pode ser entendida como um dos componentes ou elementos de um espaço (comercial, público, doméstico ou virtual) que proporciona (ou não) um bom acolhimento (hospitalidade).

\section{Procedimentos metodológicos}

Para o desenvolvimento deste artigo, optou-se pela pesquisa de natureza qualitativa, visto que o intuito é levantar opiniões diversas a respeito do assunto proposto. Nesse sentido, a pesquisa qualitativa "[...] trabalha com o universo de significados, motivos, aspirações, crenças, valores e atitudes [...] que não podem ser reduzidos à operacionalização de variáveis" (MINAYO, 2002, p. 21-22).

Os procedimentos metodológicos estabelecidos neste trabalho seguiram as seguintes etapas: levantamento de referencial teórico sobre o tema; observação participante dos au- 
tores no objeto de estudo; intervenção em campo por meio de questionário semiestruturado aplicado a uma amostra representativa de usuários do espaço e, por fim, análise dos resultados para inferir tendências.

No que se refere ao levantamento bibliográfico, buscaram-se livros, artigos científicos, dissertações de mestrado e sites em diferentes bases de dados (DEDALUS, SIBI USP, GOOGLE SCHOLAR e TESES USP) que se relacionam com o universo estudado (conceitos e espaços da hospitalidade, as dimensões da comunicação e o Parque Ibirapuera).

Obtiveram-se informações sobre a comunicação visual (sinalização por meio de placas, mapas, folhetos informativos etc.) no Parque Ibirapuera, por meio da observação participante dos pesquisadores, a qual "[...] envolve olhar. [...] Algumas vezes, as pesquisas observacionais são chamadas de método não intrusivo, uma vez que geralmente não existe o envolvimento com o observado, que pode nem estar ciente de que está sendo observado" (VEAL, 2011, p. 239).

Em busca de entendimento mais amplo sobre a importância da comunicação visual para tornar-se um ambiente hospitaleiro, aplicou-se uma pesquisa de campo no Parque Ibirapuera com os visitantes que frequentam o local. Aqui cabem alguns esclarecimentos estatísticos: população ou universo é o "[...] conjunto de unidades sobre o qual desejamos obter informação", enquanto que amostra é "[...] todo subconjunto de unidades retiradas de uma população para obter a informação desejada" (VIEIRA, 2015, p. 129).

No Parque Ibirapuera, a população de usuários é muito grande (cerca de 150 mil visitas por final de semana) $)^{2}$ e, portanto, impossível de ser analisada em sua totalidade, pois seria inviabilizada pelo "[...] custo e [pela] demora para obter os dados". Assim sendo, optou-se pela metodologia de amostragem, pelo "[...] fato de que estudar cuidadosamente uma amostra [amostragem] tem mais valor científico do que estudar rapidamente toda a população [censo] (VIEIRA, 2015, p. 130).

Para a realização desta pesquisa de campo, foi aplicado um questionário semiestruturado com sete perguntas, sendo duas abertas e cinco fechadas, quanto a comunicação visual (sinalização) do Parque Ibirapuera. O questionário obedece à seguinte estrutura: as duas primeiras questões estão centradas em estabelecer o perfil do público entrevistado, enquanto as outras cinco, dão enfoque na opinião deles sobre o tema de pesquisa. Tal aplicação ocorreu na amostra de 68 respondentes da população de visitantes do parque, o que representa $90 \%$ de nível de confiança e $10 \%$ de erro amostral. ${ }^{3}$

\section{ANÁLISE E disCuSSÃo dOS DAdOS}

Criado em 1954 por Ciccillo Matarazzo, o Parque Ibirapuera oferece um espaço público de $1.584 .000 \mathrm{~m}^{2}$, constituído de vegetação, lagos, ciclovias, pista de corrida, academia ao ar livre, playgrounds, lanchonetes, museus, esculturas, auditório etc. (BARONE, 2009;

2 Notícia completa em:<http://www.brasil.gov.br/turismo/2015/08/ibirapuera-esta-entre-os-10-melhores-parques-urbanos-do-mundo-segundo-the-guardian>.

3 Calculadora utilizada para cálculo do nível de confiança e do erro amostral: $<$ http://www.publicacoesdeturismo.com.br/calculoamostral/s. 
NUNES JUNIOR, 2009). Aberto todos os dias da semana, das $5 \mathrm{~h}$ às $00 \mathrm{~h}$, os visitantes têm acesso gratuito ao parque, pelos portões 2, 3, 4, 6, 7A e 10 (entrada de pedestres) e 3 e 7A (entrada de veículos). ${ }^{4}$

O parque recebe muitos usuários - mais de 14 milhões de visitas por ano ${ }^{5}-$, com um perfil bem diversificado. Sendo assim, é possível notar a presença de crianças, jovens, idosos, casais, famílias inteiras, esportistas, dogwalkers, entre outros (NUNES JUNIOR, 2009), que utilizam o parque para o usufruto do lazer em seu tempo livre.

Em outras palavras, entende-se esse "lazer" como:

[...] um conjunto de ocupações às quais o indivíduo pode entregar-se de livre vontade, seja para repousar, seja para divertir-se, recrear-se e entreter-se ou ainda para desenvolver sua formação desinteressada, sua participação social voluntária ou sua livre capacidade criadora, após livrar-se ou desembaraçar-se das obrigações profissionais, familiares e sociais (DUMAZEDIER, 1980, p. 19).

Existem diversos exemplos de atividades (ocupações) de lazer que são praticadas no parque. Alguns visitantes preferem caminhar e correr ao ar livre, andar de bicicleta, patins e skate, praticar exercícios físicos nos equipamentos do parque ou com o auxílio de personal trainner. Outros, utilizam o espaço para tirar fotografias para books de casamento, realizar festas de aniversário infantis e fazer piquenique com os amigos. Ainda existem aqueles que optam por participar de exposições oferecidas no Museu de Arte Moderna (MAM) e na Oca, e conhecer mais sobre Astronomia em observações noturnas no Planetário Aristóteles Orsini.

Independente de qual seja o interesse cultural do visitante - físico-esportivo, social, intelectual, manual ou artístico (DUMAZEDIER, 1980) relacionado à determinada atividade -, o parque pode ser utilizado para a realização de quaisquer outras práticas de lazer. Inclusive, o lazer enquanto veículo de educação, proporciona desenvolvimento pessoal e social aos indivíduos, pois não apenas diverte e entretém, mas também ensina; torna possível o aprendizado por meio dessas atividades (MARCELLINO, 2006).

Embora seja palco para práticas de lazer, muitas vezes realizadas por moradores locais, o Parque Ibirapuera também contempla o interesse cultural turístico (CAMARGO, 1986), visto que é considerado um importante ponto turístico da cidade de São Paulo. A grande quantidade de turistas que o parque recebe está interessada em conhecer essa "[...] área para recreação" "de fácil acesso", que oferece "diversos espaços culturais" (ROCHA, 2001, p. 85), como o Museu Afro Brasil, a Escola de Astrofísica, o Museu de Arte Contemporânea (MAC), o planetário, entre outros.

Por ser um parque urbano de livre acesso a qualquer público, o Parque Ibirapuera pode ser classificado como espaço social público - elemento da categoria "espaços sociais" da hospitalidade (CAMARGO, 2004). Logo, o parque assume a posição de "anfitrião", e os visitantes se tornam "hóspedes". Mas para ser um ambiente hospitaleiro é preciso que

4 Site oficial do Parque Ibirapuera: $<$ https://parqueibirapuera.org/parque-ibirapuera/parque-ibirapuera/ $>$.

5 Notícia completa em:<http://www1.folha.uol.com.br/banco-de-dados/2017/09/1873255-aos-63-ibirapuera -e-o-parque-mais-visitado-da-america-latina.shtml $>$. 
o Parque Ibirapuera apresente alguns elementos típicos da hospitalidade, por exemplo, a comunicação visual.

Para a análise da comunicação visual no Parque Ibirapuera, observou-se a sinalização em geral (placas, mapas, panfletos informativos etc.), tanto nas entradas quanto no interior do mesmo, pois conforme aponta Salgado (2013, p. 50), a sinalização está “"[...] focada na missão de transmitir, ou antes, assegurar, estabilidade e tranquilidade de percurso, deslocamento e controle do ambiente pelo usuário".

Por meio da observação participante no Parque Ibirapuera, constata-se em seus portões de entrada algumas placas indicativas com o respectivo número do portão, bem como seu regulamento de uso. A Figura 1 nos traz um exemplo: uma placa (de cor verde) com número do portão (em cor amarela) à esquerda, e outra placa (de cor verde) com o regulamento do parque (em cor branca) à direita.

Figura 1 - Placas na entrada do portão 4, no Parque Ibirapuera.

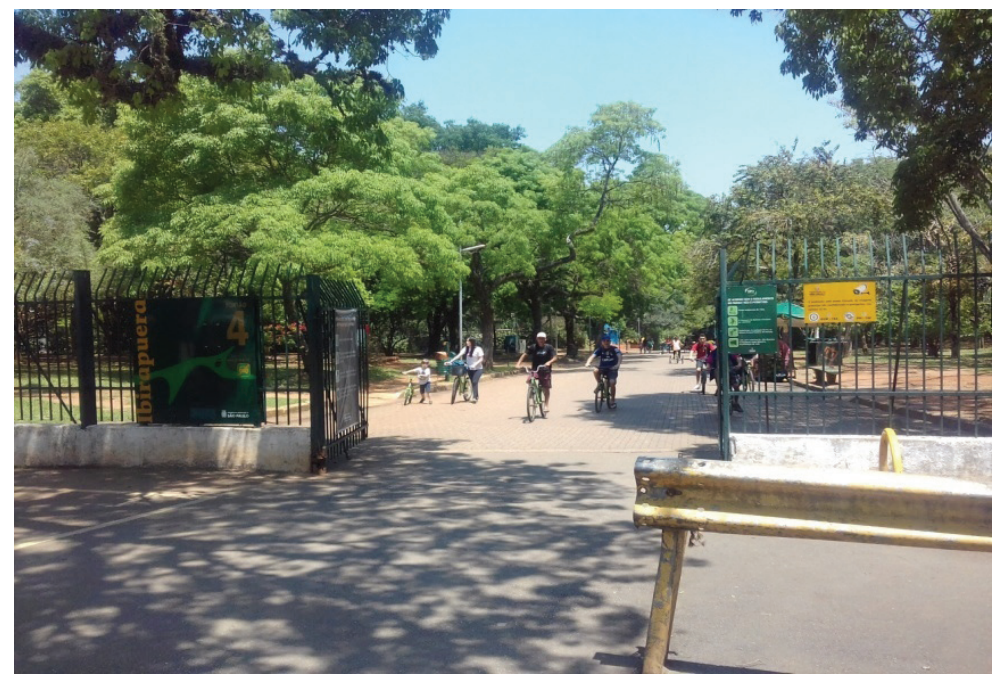

Fonte: Os autores (2017).

Com relação à comunicação visual disposta dentro do parque, nota-se que as placas de sinalização referente às atrações do parque, como os playgrounds, a academia ao ar livre, o planetário, os museus etc., encontram-se muito espalhadas ao redor do local. Dessa forma, os visitantes são obrigados a percorrerem um longo percurso, tanto para que se deparem com elas quanto para se dirigirem até seu destino, conforme ilustra a Figura 2. 
Figura 2 - Percurso do Portão 9 (sem sinalização), no Parque Ibirapuera.

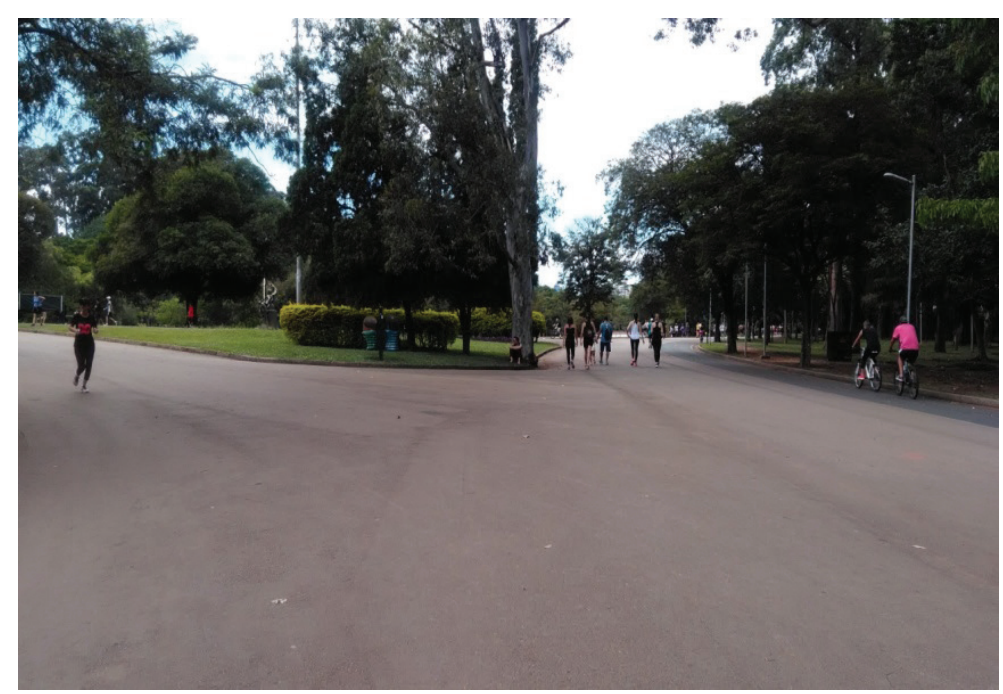

Fonte: Os autores (2017).

Não há mapas impressos disponíveis nas entradas do parque, mas há distribuição de alguns desses exemplares no Museu de Arte Moderna (MAM), ou seja, só para aqueles que conseguirem encontrar o museu; o restante dos usuários permanece sem orientações. Já os poucos (e quase inexistentes) mapas fixos que estão extremamente espalhados pelo parque (Figura 3), muitas vezes, confundem mais do que orientam os usuários, pois apresentam diversas informações em um espaço relativamente pequeno. Além disso, não foi observada a distribuição de panfletos informativos ao redor do Parque Ibirapuera.

Figura 3 - Mapa fixo na entrada do portão 4, no Parque Ibirapuera.

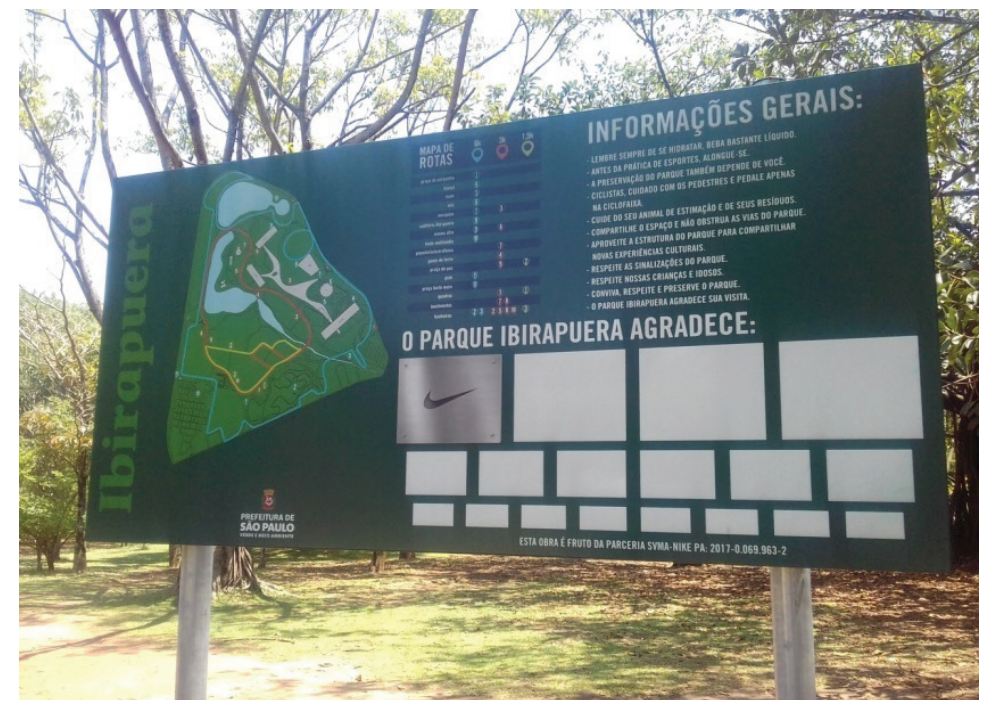

Fonte: Os autores (2017). 
Outro ponto a ser destacado sobre as poucas placas que existem dentro do parque é que, a maioria delas, agrega muitas informações. Uma mesma placa indica várias direções distintas (Figura 4) - como se elas tentassem "compensar" todo o trajeto percorrido sem algum tipo de orientação -, o que acaba confundindo ainda mais os visitantes.

Figura 4 - Placas no Parque Ibirapuera.

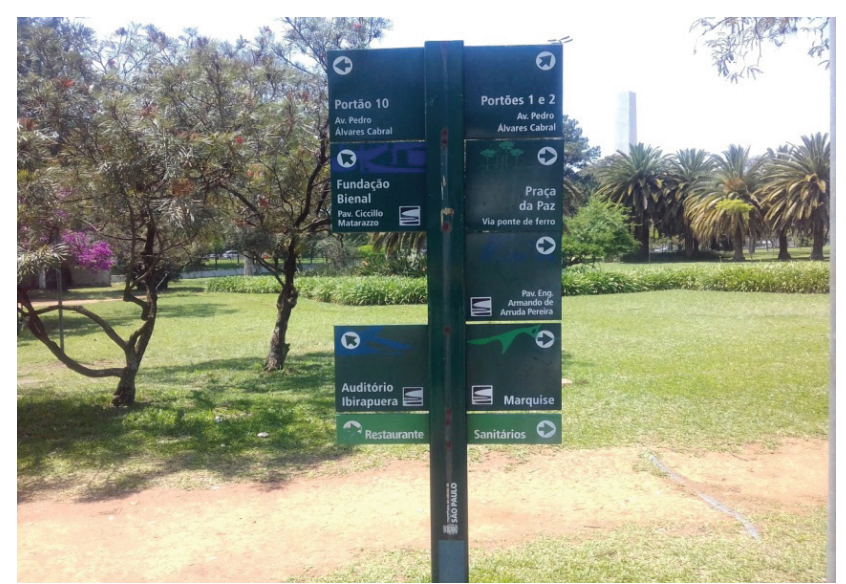

Fonte: Os autores (2017).

Além do número de placas ser reduzido e bem espalhado pelo parque, ainda há estruturas de ferro (Figura 5) sem a implementação de placas (provavelmente existiam sinalizações nessas estruturas, mas foram degradadas ou vandalizadas); estruturas que poderiam ser úteis para dar mais informações sobre o ambiente.

Figura 5 - Estrutura de placas sem sinalização, no Parque Ibirapuera.

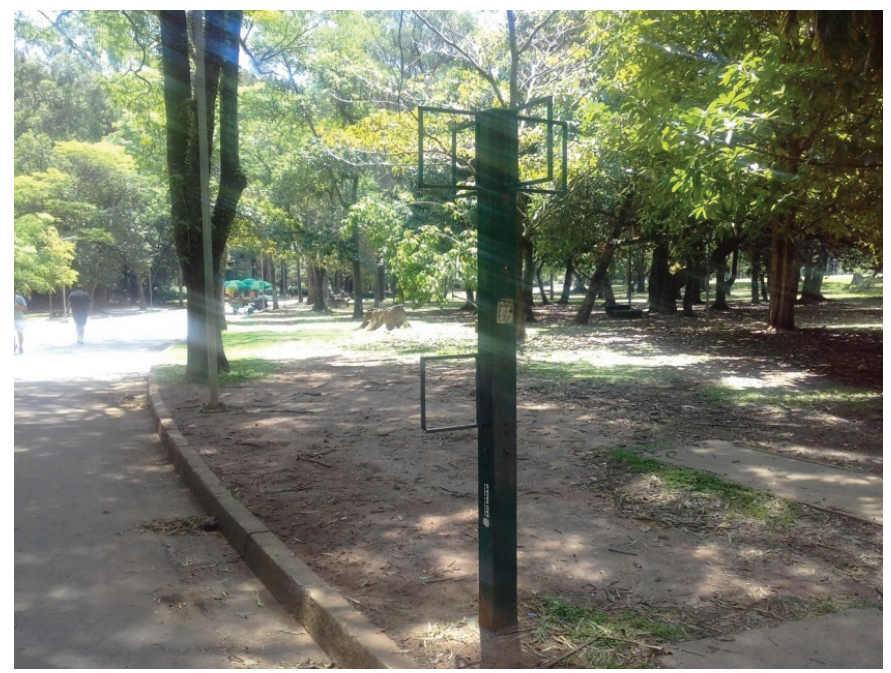

Fonte: Os autores (2017). 
Essa precariedade na comunicação visual do Parque Ibirapuera deve ser encarada como um problema real a ser resolvido, pois o fato do visitante se sentir desorientado ou ter a "[...] sensação de estar perdido pode ser uma experiência assustadora e pode levar a reações emocionais muito graves como ansiedade e insegurança" (SALGADO, 2013, p. 50). A desorientação com a sensação de insegurança pode, também, levar o usuário a não frequentar mais o parque, uma vez que ele não se sente acolhido e seguro no mesmo - consequência que poderia ser evitada com uma melhor utilização dos meios de comunicação visual.

A eficiência da comunicação enquanto orientação à mobilidade espacial é essencial para a otimização da receptividade do turista estrangeiro na cidade-alvo, uma vez que as informações podem ser simultaneamente motivadoras e viabilizadoras de seu deslocamento em direção aos pontos turísticos (ULIAN; DIAS, 2001, p. 67).

Após a observação participante, inferiu-se que o bom uso da comunicação visual no Parque Ibirapuera não só tornaria o ambiente mais hospitaleiro como também evitaria que ele se tornasse um "não lugar" para os visitantes - um local que "[...] permite uma grande circulação de pessoas, coisas e imagens [...] do qual ninguém faz verdadeiramente parte" (SÁ, 2014, p. 211).

Já a aplicação do questionário semiestruturado com os usuários do Parque Ibirapuera buscou levantar dados que corroborem com o que fora constatado por meio da observação participante dos autores. Para tanto, conta com sete questões (duas abertas e cinco fechadas), as quais traçam o perfil dos usuários do parque, bem como suas opiniões sobre o tema deste artigo.

A primeira pergunta determina o sexo dos entrevistados, respectivamente, $68 \%$ do sexo feminino e $32 \%$ do sexo masculino. Já a segunda questão estabelece a faixa etária dos respondentes: praticamente metade dos entrevistados ( $48 \%$ deles), está na faixa de 21 a 40 anos. Embora predomine o público jovem entre os respondentes, o público que frequenta o Parque Ibirapuera é misto, recebendo tanto visitantes mais jovens quanto mais velhos como demonstra a variação da idade dos respondentes (entre 20 e 60 anos de idade).

A partir da terceira pergunta do questionário, é possível analisar a frequência que o público visita o parque; grande parte dos visitantes (74\%), frequenta o parque esporadicamente. $\mathrm{O}$ fato de muitos entrevistados não utilizarem o parque continuamente não torna a pesquisa menos eficaz; ao contrário, pode ser um indicativo de que as pessoas não se sentem acolhidas por esse ambiente e por isso não o visitam com mais frequência.

Na questão número 4, ilustrada pelo Gráfico 1, questiona-se sobre a opinião dos visitantes com relação à comunicação visual do parque. Apenas $20 \%$ dos entrevistados a classifica como "boa", e 1\% a classifica como "ótima". Demais respondentes consideram a sinalização como "regular" (47\%), "ruim" (12\%) ou "péssima" (20\%), atingindo um total de $79 \%$. Isso comprova que a comunicação visual (sinalização) do parque é precária e necessita de atenção especial. 
Gráfico 1 - Distribuição da classificação "sinalização" no Parque Ibirapuera.

\section{Comunicação visual do parque:}

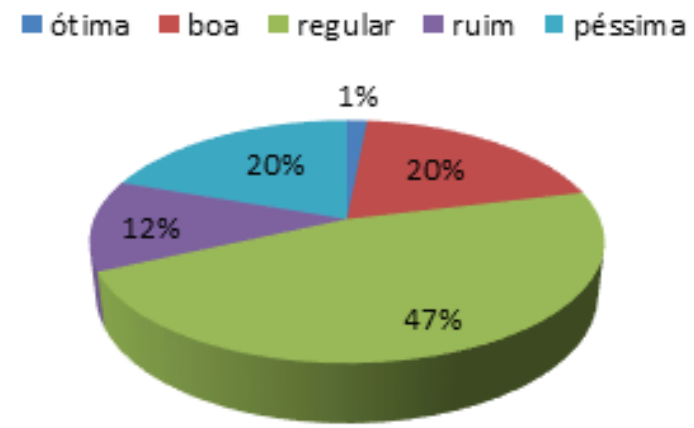

Fonte: Os autores (2017).

A questão 5, ilustrada pelo Gráfico 2, diz respeito aos visitantes se sentirem perdidos dentro do parque, exatamente pela falta de sinalização no local e o resultado não surpreende: quase $70 \%$ dos entrevistados já se sentiram perdido no parque. Muitos respondentes justificaram a fácil perda de direção exatamente pelo fato de o parque ser muito extenso e por dispor de pouca sinalização, especialmente placas.

Gráfico 2 - Distribuição da classificação "perdido no parque" no Parque Ibirapuera.

\section{Se sentiu perdido no parque:}

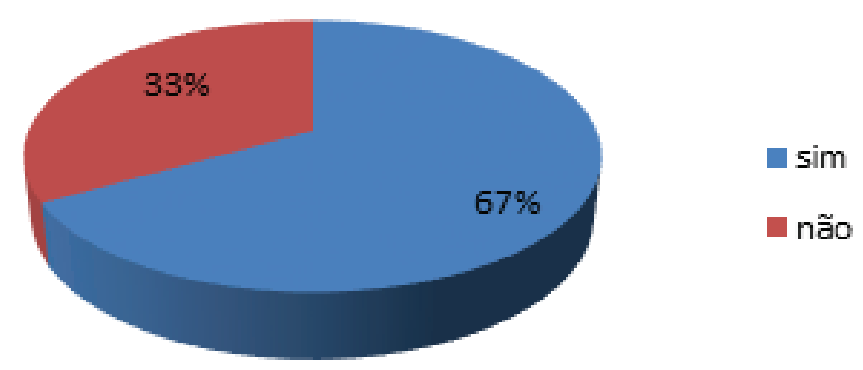

Fonte: Os autores (2017). 
A questão 6 dá enfoque aos visitantes que se sentiram perdidos no parque e onde eles conseguiram encontrar as informações ou direções que estavam procurando. Conforme o Gráfico 3, nota-se que os vendedores ambulantes (48\%) são os que mais ajudam visitantes "perdidos", seguidos de $37 \%$ de outros próprios visitantes e, apenas $15 \%$ dos visitantes conseguem obter as informações que precisam com funcionários do próprio parque.

Gráfico 3 - Distribuição da classificação "onde conseguiu informações" no Parque Ibirapuera.

\title{
Onde conseguiu informações:
}

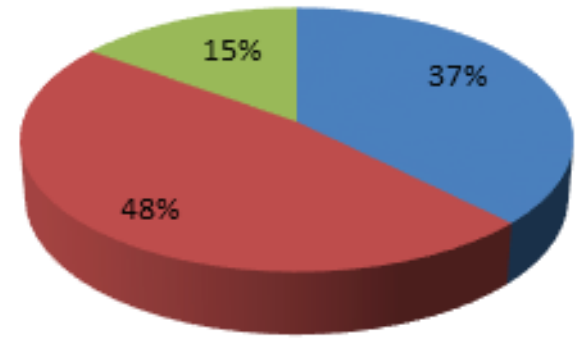

\author{
visitantes do parque \\ - vendedores ambulantes \\ - funcionários do parque
}

Fonte: Os autores (2017).

A última questão, de número 7, teve como objetivo questionar se os visitantes acreditam que a sinalização do parque é importante para que as pessoas se sintam bem acolhidas por ele. Na visão de $95 \%$ de todos os entrevistados, a comunicação visual (sinalização) é um dos elementos importantes para que o ambiente seja mais hospitaleiro, principalmente quando se leva em consideração que o Parque Ibirapuera é um espaço público que recebe muitos turistas.

É interessante notar também que os resultados obtidos para este artigo também dialogam com a pesquisa realizada pelas pesquisadoras Ulian e Dias (2001), a qual já havia apontado que o Parque Ibirapuera tinha péssima sinalização para turistas estrangeiros. Conforme apontam as autoras, a "[...] sinalização [do parque] assim como toda a sinalização de acesso dentro da cidade, limita-se aos nomes dos locais" e isso porque, na época, “[...] o segundo lugar de maior menção nos questionários [como principais destinos turísticos de São Paulo] foi o Parque Ibirapuera" (ULIAN; DIAS, 2001, p. 62). Essa pesquisa também analisou a relação dos transportes com a qualidade da comunicação em si, chegando à mesma conclusão de nosso estudo: bastante precária, quando existente.

Cabe observar que, além das sinalizações - relacionadas à comunicação visual -, disponíveis no parque, pode-se mencionar a utilização de recursos tecnológicos para o auxílio do público com relação à localização e aos atrativos do parque. O próprio Parque Ibirapue- 
ra desenvolveu um aplicativo de celular, que tem como proposta "[...] te mostrar o melhor do parque quando você estiver aqui. Saiba onde você está no parque, onde encontrar o que busca e confira a programação de eventos com exposições, shows e muito mais" ". No entanto, ao baixar o aplicativo, observou-se que os eventos oferecidos no parque estão desatualizados (datados em dezembro/2017), as informações sobre a localização dos atrativos estão confusas e o próprio aplicativo está disponível apenas no idioma português.

Assim, analisando os resultados, pode-se dizer que para um visitante do parque que fale o idioma português é bem difícil se localizar dentro do Ibirapuera. Pode-se extrapolar essa constatação e afirmar que essa dificuldade é intensificada quando se trata de turistas estrangeiros, já que a pouca sinalização (quando existente) não está disponível em outros idiomas. E, novamente, essa constatação não se limita apenas à comunicação visual física e/ou impressa disponível no parque. Ao baixar o aplicativo de celular desenvolvido pelo próprio parque, também só há disponível o idioma português para as informações escassas e desatualizadas ali apresentadas.

\section{CONSIDERaÇões FINAIS}

Conclui-se que a comunicação visual é um dos elementos importantes que tornam um ambiente mais hospitaleiro e, até mesmo vital, no caso de turistas estrangeiros, já que "[...] sua orientação depende do sistema informativo que garante ou dificulta o acesso a esses locais [turísticos]" (ULIAN; DIAS, 2001, p. 67). No caso do Parque Ibirapuera, ele não parece um ambiente tão hospitaleiro quanto poderia ser dada sua importância turística para a cidade de São Paulo.

A comunicação visual - observada por meio da sinalização em geral, como placas, mapas, panfletos informativos etc. -, quando existente, pode ser considerada insuficiente diante da dimensão do Parque Ibirapuera. Devido à falta de sinalização, informação e preocupação para com o público frequentador, muitos visitantes classificam a comunicação visual do parque como "regular", "ruim" ou "péssima", o que aponta oportunidades de melhoria na mesma.

Assim, propõem-se as seguintes soluções a fim de tornar o parque um espaço público mais hospitaleiro: a inserção de sinalização em locais estratégicos do parque, a promoção do uso do aplicativo de celular desenvolvido pelo próprio parque e a melhoria do mesmo, bem como, a contratação de guias de turismo e de animadores socioculturais para atender e orientar os visitantes. O ideal é que a sinalização e o aplicativo sejam disponibilizados em português (língua nativa), inglês e espanhol (línguas universais), e que os guias de turismo e animadores socioculturais tenham o domínio das mesmas línguas.

Para a inserção da sinalização em local estratégico, sugere-se que em cada portão tenha uma placa com a relação dos portões com os respectivos pontos turísticos e atividades

${ }_{6}$ Site do Parque Ibirapuera Conservação: $<$ https://parqueibirapuera.org/ibiraconservacao/aplicativo-do -parque/s. 
disponibilizadas no parque, bem como mapas impressos com essas mesmas informações. Dessa forma, o visitante saberá se está no portão mais próximo da atração que deseja visitar. Além disso, recomenda-se que as bifurcações tenham placas indicativas dos atrativos do parque, de modo a evitar a poluição visual e a não confundir os visitantes com informações excessivas.

Já na promoção do aplicativo, a sugestão é fazer uma campanha incentivando o uso do aplicativo, assim como o envio de sugestões para melhorar o mesmo, pois assim os próprios visitantes poderão contribuir para o seu aperfeiçoamento. Inclusive, uma das possibilidades é integrar ao aplicativo, informações sobre eventos (por exemplo, as Caminhadas Monitoradas) que ocorrem no parque e que são postados no perfil do Parque Ibirapuera no Facebook. $^{7}$

Por fim, mas não menos importante, a proposta é contratar guias de turismo e animadores socioculturais, a fim de exercerem a função de "educadores" e não de mercadores (MARCELLINO, 2007). Por meio da criação de atividades socioeducativas e de roteiros turísticos do parque, tais atores podem receber, orientar e ensinar os visitantes, bem como engajá-los a participar dessas e de outras atividades que o parque propicia, quer pela iniciativa pública quer com parcerias na iniciativa privada.

Assim, entende-se que este artigo aponta um possível caminho em direção a um Parque Ibirapuera mais hospitaleiro, o que certamente atrairá mais público, bem como ajudará a fidelizar o público atual - já que o "hóspede" poderá se sentir mais confortável e acolhido. Representa ainda uma oportunidade para a reflexão sobre o papel do lazer nos parques urbanos de grandes cidades, como é o caso de São Paulo, destacando seu caráter educativo a partir de uma efetiva comunicação sobre a miríade de possibilidades em termos de atividades no usufruto do tempo livre.

\section{REFERÊNCIAS}

BARONE, A.C.C. A oposição aos pavilhões do Parque Ibirapuera (1950-1954). Revista Anais do Museu Paulista. São Paulo: v.17, n.2, p. 295-316, jul./dez. 2009.

BENI, M. Análise estrutural do turismo. São Paulo: SENAC, 1998.

CAMARGO, L.O.L. O que é lazer. São Paulo: Brasiliense, 1986.

. Hospitalidade (Coleção ABC do Turismo). São Paulo: Aleph, 2004.

. Os interstícios da hospitalidade. Revista Hospitalidade. São Paulo, v.XII, n. especial, p. 42-69, mai. 2015.

Perfil do Parque Ibirapuera Conservação no Facebook: $<$ https://pt-br.facebook.com/pg/ibiraconservacao/ events/?ref=page internal $>$. 
DENCKER, A.F.M. Comunicação e Hospitalidade nas Organizações. In: PINHO, J.B. (org.). Comunicação Brasileira no Século XXI - Intercom: Ação, Reflexão - vol. 2 - A clava forte. São Paulo: Intercom 30, 2007, p. 89-105.

DUMAZEDIER, J. Valores e conteúdos culturais do lazer. São Paulo: SESC, 1980.

GRINOVER, L. Hospitalidade: um tema a ser reestudado e pesquisado. In: DIAS, C.M.M. (org.). Hospitalidade: reflexões e perspectivas. São Paulo: Manole, 2002, p. 25-38.

GUIMARÃES, G.; CAMARGO, L.O.L. Formas de avaliar a capacidade de ser hospitaleiro por meio das preferências comportamentais e da empatia. Revista Turismo e Desenvolvimento. São Paulo: n.27/28, p. 123-132, 2017.

JÜNGE, J. Comunicação Visual e Paisagem Urbana: Estudo sobre mídias e arte no espaço público. Dissertação (Mestrado em Urbanismo, História e Arquitetura da Cidade) Universidade Federal de Santa Catarina, Florianópolis, 2011.

MARCELLINO, N.C. Estudos do lazer: uma introdução. 4 ed. Campinas, SP: Autores Associados, 2006.

. Lazer e cultura. Campinas: Alínea, 2007.

MAUSS, M.; LÉVI-STRAUSS, C.; MARQUES, A.F. Ensaio sobre a dádiva. Lisboa: Edições 70, 2008.

MINAYO, M.C.S. (Org.). Ciência, técnica e arte: o desafio da pesquisa social. In: MINAYO, M.C.S. et al. Pesquisa Social: teoria, método e criatividade, 21. ed. Petrópolis: Vozes, 2002, cap. 1, p. 21-22.

NUNES JUNIOR, P.C. Espaço para o tempo livre: Considerações sobre o lazer e apropriação do espaço urbano no Parque do Ibirapuera. Dissertação (Mestrado em Educação Física) - Universidade Estadual de Campinas, Campinas, 2009.

OMT - Organización Mundial del Turismo (1995). Concepts, Definitions and Classifications for Tourism Statistics: a Technical Manual, Madrid.

ROCHA, Y.T. Parques Urbanos: um recorte de São Paulo e suas potencialidades para o Turismo. Revista GEOUSP. São Paulo, n.9, p. 79-89, 2001.

SÁ, T. Lugares e não lugares em Marc Augé. Tempo Social - Revista de Sociologia da USP. São Paulo: v.26, n.2, p. 209-229, 2014.

SALGADO, R. Projeto de sinalização em parques urbanos: sistematização de elementos estruturadores a partir de exemplos no município de São Paulo. Dissertação (Mestrado em Arquitetura e Urbanismo) - Universidade de São Paulo, São Paulo, 2013. 
SILVA, L.M.G.; BRASIL, V.V.; GUIMARÃES, H.C.Q.C.P.; SAVONITTI, B.H.R.A.; SILVA, M.J.P. da. Comunicação não-verbal: reflexões acerca da linguagem corporal. Revista Latino-Americana de Enfermagem. Ribeirão Preto: v.8, n.4, p. 52-58, 2000.

TRIGO, L.G.G. Turismo e qualidade: tendências contemporâneas (Coleção Turismo). Campinas: Papirus, 1993.

ULIAN, F.; DIAS, L.V. Comunicação visual e acessibilidade do turista estrangeiro na cidade de São Paulo. Revista Turismo em Análise. São Paulo: v.12, n.1, p. 55-71, mai. 2001.

URRY, J. O olhar do turista. São Paulo: Estúdio Nobel; SESC, 1996.

VEAL, A.J. Metodologia de Pesquisa em Lazer e Turismo. São Paulo: Aleph, 2011.

VIEIRA, S. Estatística básica. São Paulo: Cengage Learning, 2015.

\section{Dados dos Autores:}

\section{Karine Regina Facini}

Mestranda em Turismo no Programa de Pós-Graduação da Escola de Artes, Ciências de Humanidades da Universidade de São Paulo. Membro do Grupo Interdisciplinar de Estudos do Lazer da Universidade de São Paulo. São Paulo/SP - Brasil. karine.facini@usp.br

\section{Danilo dos Santos Lopes}

Pós-Graduado em Gestão e Governança da Tecnologia da Informação pelo Serviço Nacional de Aprendizagem Comercial. São Paulo/SP - Brasil. danilo.santos.lopes@usp.br

Ricardo Ricci Uvinha

Doutor em Ciências da Comunicação pela Universidade de São Paulo. Docente e Pesquisador da Universidade de São Paulo nas áreas de Ciências da Saúde e Ciências Sociais Aplicadas. Orientador permanente do Mestrado e Doutorado Acadêmico nos Programas de Pós-Graduação em Turismo e de Pós-Graduação em Ciências da Atividade Física, ambos na Escola de Artes, Ciências e Humanidades. São Paulo/SP - Brasil. uvinha@usp.br

Submetido em: 16-10-2018

Aceito em: 12-4-2019 